\title{
Understanding Community Collective Behaviour Through Social Media Responses: Case of Sunda Strait Tsunami, 2018, Indonesia
}

\author{
Farah Pasha Salsabilla ${ }^{1}$, Dyah Rahmawati Hizbaron ${ }^{1 *}$ \\ ${ }^{1}$ Department of Environmental Geography, Faculty of Geography, Universitas Gadjah Mada, 55281, Bulaksumur, Yogyakarta \\ Indonesia
}

\begin{abstract}
The Sunda Strait Tsunami which occurred on 22nd December 2018 is one among too many examples of a rapid on-set disaster that attracted public attention through Twitter. This sudden event had a massive impact on parts of the west coast of Banten Province, Indonesia. Therefore, this research aimed to evaluate the collective response reflected on Twitter due to the 2018 Sunda Strait Tsunami. Previous studies shows the utilization of crowd sourcing data from social media for community capacity and quick assessment of disaster impacts. Therefore, the characteristics of people's responses on social media based on spatio-temporal attributes needs to be understood first to build better understanding about the information that can be used for emergency response strategies consideration. This research method involved a spatial statistics approach, while data collection and descriptive analysis were carried out based on Twitter word cloud data. This analysis showed that temporally, the highest number of tweets was generated at the beginning of the disaster period with downward trend into the end of phase. As for spatially, people in directly affected areas by the disaster tend to give negative sentiments as their expression of sadness and fears towards the disaster. The content of the tweets involved asking for help, reporting on the current situation, and confirming the news on accounts belonging to government agencies. Furthermore, people in areas that were not directly affected produced tweets with more positive sentiment with expressions of condolences, sympathy, gratitude and invitations for volunteers and social actions.
\end{abstract}

\section{Introduction}

On December 22, 2018, at 21.03 Local Time or 14.03 UCT, a tsunami disaster with waves reaching 13.5 meters struck the coastal areas of South Lampung, Banten, and the surrounding islands of Anak Krakatau Volcano. The Tsunami post-survey at Banten showed 5.8 meters run-up with an inundation distance up to 330 meters away[1]. The hardest-hit area was the west coast of Banten Province and the southern coast of Lampung Province[2]. However, the Tsunami also caused an impact to the surrounding islands, such as Sertung, Rakata, and Panaitan Islands located around the Anak Krakatau Volcano. This tsunami wave was eventually identified to have been triggered by the volcanic flank failure at the Anak Krakatau Volcano[2][3] which created sub-aerial flanks[4]. Banten was likely less inundated due to the existing trace of coastal defense along the seaside.

The western coastal area of Banten was hit by tsunami waves without any significant warning, causing many casualties and damage. Figure 1 indicated some areas damaged due to the disaster occurrence, especially at Pandeglang and Serang District, Banten, West Java, Indonesia (Figure 1). It caused a 437 death toll, 1,143 people injured, and 5,361 displaced. Furthermore, physical damage to 558 houses, 8 hotels, 60 stalls and 350 boats occurred[5]. The infrastructure was also disconnected which caused damage to 248 power stations and 42 electricity poles[6]. Sumur Subdistrict in Pandeglang District, was the hardest hit area, which was indicated by a significant change in land use from settlements and vegetation cover to open land[7]. Additionally, the impact of the tsunami also caused the cutting off of several road accesses and isolated areas to Pandeglang and Serang.

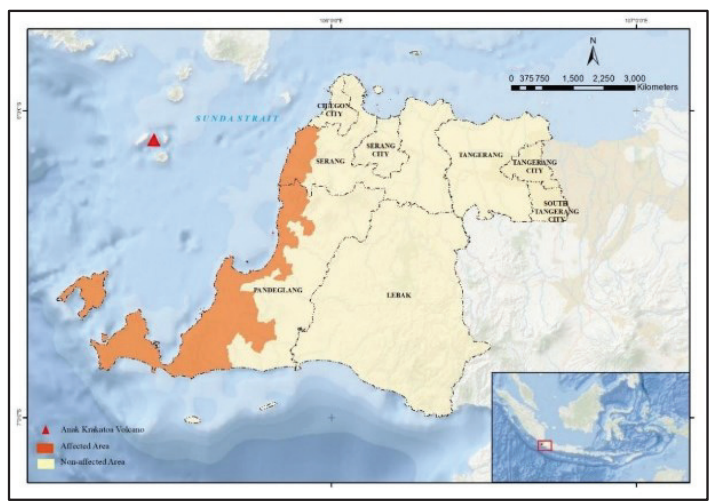

Fig. 1. Affected area by the Sunda Strait tsunami in Banten Province, Indonesia

\footnotetext{
* Corresponding author: dyah.hizbaron@ugm.ac.d
} 
To reduce the impact of disasters, information sourced from the community at the scene of the postdisaster situation is very important in disaster response and recovery[8]. Therefore, as a product of technological developments in the field of communication, social media has advantages in terms of real-time data availability and unlimited audience reach. Its popularity and ability in information dissemination renders it a potential channel in disaster management communication involving a wide audience, and the provision of valuable sources of information for rapid assessment. Social media for emergency response management is widely used for distributing the latest information on disasters, building public awareness, and raising moral and material support[9].

The emergency response shown by a community is an important social dimension of disaster management. The collective response pattern formed will add references for policymakers in considering a more effective emergency response strategy by involving community dynamics. This study aims to evaluate the response characteristics of the 2018 Sunda Strait Tsunami, specifically in the area of Banten, Indonesia. Furthermore, the research objective was based on utilizing crowdsourcing data from Twitter, processed and analyzed in a spatio-temporal perspective. It applied social media data to capture the local capacity during an emergency. As the scientific documents on the subject of disaster capacity due to Sunda Strait Tsunami were not sufficient for capture, this research takes a contributing initiative.

\section{Research Framework}

As communication technology interventions are increasingly attached to the life of modern society, people tend to be more open in sharing their opinions and activities on social media. This underlies the research idea of spatial-temporal based crowdsourcing which sees social media as a potential data source to be utilized, including for the implementation of disaster emergency response. Previous research was conducted to evaluate the preparedness of school students to the Tsunami at Banten Province, and ascertained a low disaster response capacity[10]. Furthermore, in times of disaster emergency response there is always a certain marginalized group which cannot be reached, as in the case of Japan Tsunami dated back at 2011[11]. How does social media enable us to capture on-site and offsite responses which supported the local capacity to deal with disaster? Previous research relevant to the subject in the case of urban response to tropical cyclone using Twitter indicated that the response varied according to the emergency phases[12]. Therefore, this research highlights the importance of spatial temporal data from crowd sourcing that reflects the inclusivity of responses in dealing with Tsunami.

Information on the tsunami disaster quickly spread on various communication platforms such as Twitter, which triggered various responses from users in various regions. When a disaster occurs, people tend to be more active in using social media to exchange information[13]. Nowadays, it has significantly transformed from its original needs for personal communication[14] to become part of people's daily lives[15]. It has therefore been considered sufficient to describe social dynamics[16]. Social media enables the communication of various responses uploaded by users during the disaster period. The collection of reactions of each individual on social media illustrates the collective response pattern of the community towards disasters, both in the affected and non-affected areas. Furthermore, understanding the community's emergency response was carried out at a collective level, which aims to understand the general response patterns of community groups, especially in Banten Province which are actively using Twitter. The determination of collective response of the community when facing a disaster needs to be done as an element of social dimension of the community to facilitate its use as a reference in the formulation of an effective disaster emergency response strategy.

Twitter is one of the most frequently used platforms for monitoring natural disasters[17]. As a microblogging social media, Twitter has the advantage of presenting concise and actual information. It is also equipped with a post topic sorting feature based on hashtag (\#), interaction via retweets, replies and likes, attachments of photo and video media, time information and a geo-tag feature that shows the location of the tweet being uploaded, which are important keys in exploring the public's response to data. The community utilizes this social media by sharing information such as notifications of disaster events, increasing awareness and sensitivity, reporting on actual conditions at the disaster site, building emotional support, forming a collective movement to help the needs of the affected community, and information on the mitigation and evacuation process[18][9]. In addition, community proactivity at the scene of the incident is considered a sensor that shares actual information continuously, becoming the basis for the use of crowd-sourcing data in disaster management. Information shared from the community in the field provides a big picture of the actual conditions due to disasters. This significantly influences decisions on emergency response by elements in authority[19].

The response formed immediately after a disaster significantly influences the success of disaster management[20]. In this case of Sunda Strait tsunami which had rapid on set characteristics without early warning announcements, the capability of the community and qualified policy makers to respond and act quickly when the disaster occurred affected the effectiveness of disaster management compared to only depending on existing structural mitigation[21]. The development and intervention of information technology is inevitable, therefore the development of methods by integrating technology has the potential to bring progress in the application of disaster emergency responses that require time efficiency. 
Destructive events such as disasters disrupt normal stability which then becomes a stimulant for the formation of collective response in a community during the emergency phase. In this phase, emergency response is emphasized in efforts to prevent the worsening impact of a disaster. A series of emergency response actions include activities to rescue and evacuate victims, property, fulfilment of basic needs, protection, handling of refugees, and the restoration of vital facilities and infrastructure. Furthermore, emergency response is influenced by the knowledge, capabilities and competence of each element involved in disaster management efforts, especially in crisis management when a disaster occurs[22]. The successful implementation of preparedness strategies in emergency response is mainly influenced by information, communication, and the availability of resources[23]. Understanding the characteristics of a community, including collective responses when facing disasters and their interactions with the environment, is an important aspect of disaster risk reduction[24][25]. The collective action underlies the importance of local capacity to face disaster[26].

The collective response of the affected community is manifested from a series of activities and roles, resources, and authority that the community[27]. The roles and activity aspect involves a series of actions taken immediately after a disaster occurs, and emphasizes community efforts to minimize the impact of a disaster. The second aspect relates to resource management, explaining how a community manages the available resources to deal with crises during the emergency response period, including resource allocation and distribution. The third aspect, specifically the role of the authority explains the form of the contribution of the competent agency in overcoming disasters, which is shown by the deployment and involvement of disaster management personnel, provision of basic living necessities, and activities that support the acceleration of disaster impact recovery.

Collective response determines the collective behavior of the community. The grassroot movements build-up to pursue a collective goal during crises, and involve the actions carried out to survive through the disaster[28]. This pattern shown by a community when facing disasters demonstrates their capability in reducing, absorbing, adapting and accelerating efforts to recover from the impact of disasters[29], or exacerbating the impact and hindering the post-disaster recovery process[30]. Meanwhile, disaster management is much more effective when the community organizes an emergency response quickly and accurately compared to only relying on existing physical mitigation structures[21]. An understanding of the collective behavior of a community is used by policymakers to determine the efficiency of preparedness strategies and emergency response, evaluate and allow for policy reformulation to increase community resilience to disasters in the future[31][32].

Alongside technological developments, collective response patterns can be reflected by a community on social media, especially when there are events that have a massive impact such as disasters[33]. Social media has currently transformed from what was originally intended for personal communication needs to become part of people's daily lives[15]. Therefore, the information in it represents the activities and social dynamics of society[34]. Previous research showed that there are differences in the collective responses of people in affected areas and the ones not directly affected by the disaster. Social media users which are closer to the disaster scene tend to provide valuable information[35][36]. In affected communities, volunteers from cyberspace communities use social media to connect and contribute as portals and information passers[37]. This is the concept of a spatially based Voluntary Geographical Information (VGI) data source by utilizing information from public uploads as field sensors.

Twitter is one of the most frequently accessed social media not only widely used during emergency response situations but also changes the way people create, identify, and re-share disaster information[38]. This is a social media with micro-blogging principles that sufficiently and concisely presents data. The social media also offers a hashtag (\#) feature to facilitate sorting topics, photo, and video attachments, to the source attribute where the tweet was uploaded via geotagging which is crucial in VGI data for spatial analysis of disasters that can be activated by users. The features offered by Twitter social media can be used for disaster analysis, especially during the response or emergency phase. Furthermore, information in form of responses or public opinions represented on social media were generally categorized into three main aspects, namely spatial, temporal and content[39]. The spatio-temporal analysis is related to the time attribute and geo-tag attached to the tweet. The tweet content can also be analyzed through text-based data processing, which is manifested in sentiment analysis and wordcloud form.

\section{Method}

\subsection{Data Collection}

Data crawling techniques were used to obtain raw data in form of tweets related to the topic of the Sunda Strait tsunami. Some restrictions were applied to obtain the results of the raw tweet data following the research objectives, namely through the language used, keywords, and time frames. Three keywords in Indonesian were used to find suitable topics and for narrowing the search range specifically for Indonesianlanguage tweets. The keywords used were "Tsunami Selat Sunda", "Tsunami Banten", and "Krakatau". This selection was based on keywords that were often used by government agencies and the mass media in reporting the progress of the 2018 Sunda Strait tsunami disaster[12]. The data crawling process was carried out during the Sunda Strait tsunami emergency response period, namely 22 December 2018 - 4 January 2019. The data crawling process was carried out using the Python programming language with the Twint module, which 
generated attributes including username, date and time, tweet content, tweet location, interaction counts, media attachments and hashtags.

\subsection{Data Pre-processing}

The pre-processing stage is important in text data processing techniques and is based on Natural Language Processing. Raw data tweets are unstructured data that require adjustments to facilitate the process of understanding the tweet contents. Tweets with geo-tag attributes originating from Banten Province were separated for further processing through the reduction and stemming stages. The reduction stage was carried out to duplicate tweets, unnecessary punctuation and link removal. The stemming process was performed for uniformity in lowercase and spelling improvements without changing the core meaning of the tweet. Meanwhile, the reduction and stemming processes were carried out using the Python programming language.

\subsection{Data Processing}

The identification of the characteristics of tweet sentiment that have gone through pre-processing was carried out through sentiment analysis with the Naïve Bayes algorithm. This classification works by calculating the odds predictive, based on probabilistic statistical calculations that refer to previous data reading experiences. The Naïve Bayes algorithm separates each attribute in the data and assumes all of them to be independent variables. Furthermore, this study applies supervised learning to the Naïve Bayes algorithm in classifying sentiment categories labeled positive, neutral and negative for each tweet. The classification process consisted of making an algorithm model using the python programming language at the data training stage and testing the model through data testing. A total of $90 \%$ or 327 tweets were used for training data, while $10 \%$ or 36 tweets for testing the Naïve Bayes classification. Each tweet was quantified by its polarity weight indicating positive (1), negative (-1) or neutral (0) emotion.

The sentiment characteristics were reviewed from a spatial and temporal perspective to determine the dynamics of community response. From the temporal perspective, the emergency response period was divided into 3 phases, namely phase 1 on December 22-24 2018, phase 2 on December 25-30 2018 and phase 3 on December 312018 - January 4 2019. This distribution was based on fluctuations in the number of daily tweets that indicated a shift in the locus of public attention on Twitter in response to the Sunda Strait tsunami. The geo-tag attribute embedded in each tweet was able to refer to the location up to the sub-district level. The location information contained in the geo-tagged attribute signified the location from which the tweet was uploaded, and was analyzed spatially through a Volunteered Geographical Information (VGI) based map via ArcGIS. The spatial analysis emphasized the tweet characteristics of the affected area compared to the non-affected area, and the distributions were determined through the data released by Regional Disaster Management Agency (BPBD) in Banten Province.

The response analysis was based on the tweet contents presented in wordcloud. The words that appear in wordcloud represent the most frequently used words by the community in responding to the Sunda Strait tsunami on Twitter. A larger size of a word presented in wordcloud signified a more frequent use of that word by Twitter users. Understanding the information presented in the worcloud was performed by linking the interrelationships between unstructured words that often appear, as an indication that represents the focus of people's attention at that time.

\section{Results and Discussion}

The tsunami disaster that occurred in December 2018 became one of Indonesia's Trending Topics at the time through the hashtags \#PrayforBanten and \#PrayforAnyer. These trending topics showed that the Sunda Strait tsunami received great attention from Twitter users with many related topic interactions. Some users were observed to use Trending Topics to raise irrelevant topics and embed hashtags or keywords related to the Sunda Strait tsunami. Therefore, the process of sorting tweets through reduction and stemming was highly necessary to obtain data following the research objectives. The data crawling process and data pre-processing on 3 keywords "Tsunami Sunda Strait", "Banten Tsunami" and "Krakatau" on Twitter from 22 December 2018 - 4 January 2019 produced 842 Indonesian-language tweets that were known to have geo-tagged attributes. Furthermore, about $43 \%$ or 363 tweets were known to come from Banten Province.

\subsection{Temporal Characteristics of Tweet Sentiment}

The sentiment dynamics of the Banten Province community's tweets towards the disaster are shown in graphical form (Figure 2). Tweets with positive, negative, and neutral sentiment generally showed a pattern of significant increase at the beginning of the period (Phase 1) which then declined over time. The decrease in the number of tweets represents a decrease in public attention over time compared to the initial phase of the emergency response period. 


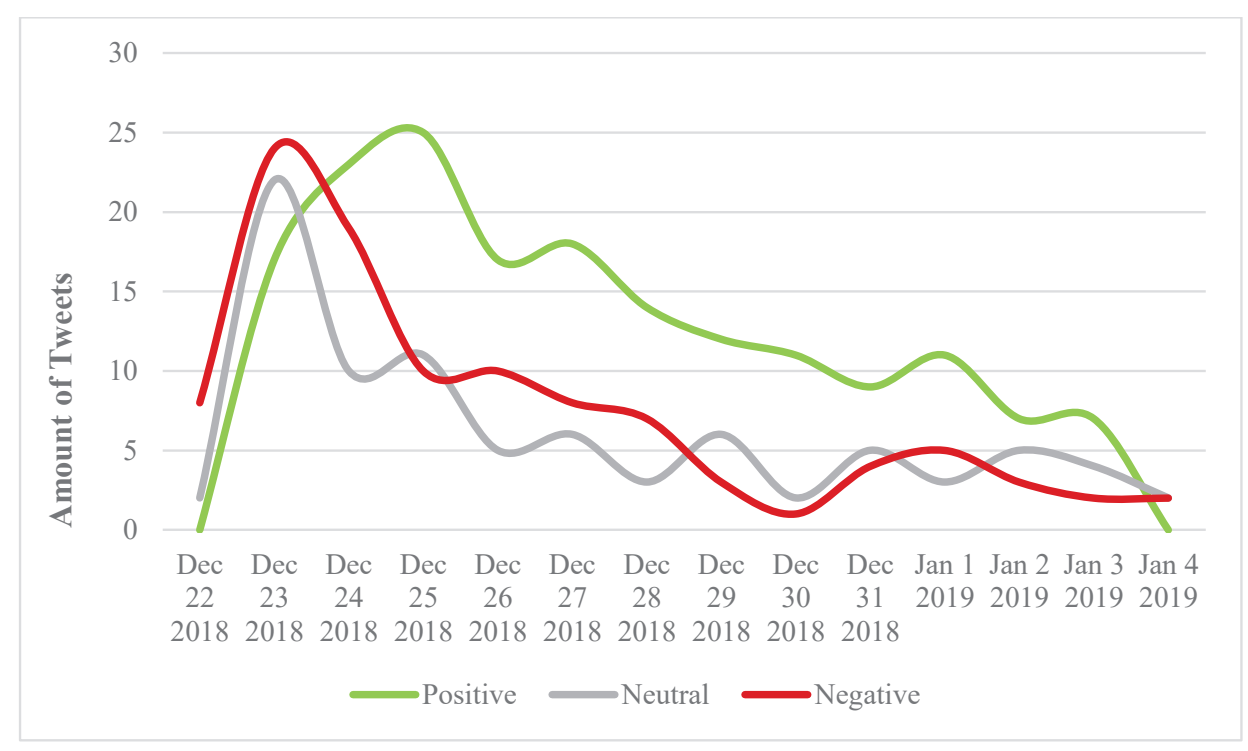

Fig. 2. Temporal distribution of tweet sentiments during the Sunda Strait tsunami emergency phase

Phase 1 (22 - 24 December 2018) showed the concentration of the number of tweets with the highest positive, neutral and negative sentiments compared to other periods. Tweets with negative and neutral sentiments reached their peak on 23 December 2018. Tweets with negative sentiments dominated this period, signifying that the tsunami disaster provided stimulation which was reflected through negative perceptions by the public. The negative sentiment was shown through tweet responses with negative contents such as panic, fear, and sadness over the occurrence of the tsunami.

Tweets with positive sentiment were dominant in phase 2, specifically December 25-30 2018, while tweets with negative and neutral sentiments began to decline. This condition may indicate the response of the community that attempts to gather support and recover from the impact of the disaster. The increase in positive sentiment tweets became a stimulant for community integration through social media which in turn influences actions on the ground. This was demonstrated through the formation of many solidarity actions to help communities in affected areas, both in form of invitations to raise donations, charity events, and volunteering.

Phase 3 started on December 31, 2018 - January 4, 2019 , showed fluctuations in the number of tweets that were positive, neutral or negative, but generally had a downward trend. Negative and neutral sentiment had slightly increased on 31 December 2018, alongside the momentum ahead of the New Year. The New Year's Day became a locus of new topics that attracted the attention of the public, associated with reflective attitudes and optimistic efforts regarding the occurrence of the Sunda Strait tsunami disaster. The number of tweets with positive sentiment were still generally dominant in this phase, which showed that public support on social media for the efforts to recover from the impact of the Sunda Strait tsunami was still continuous.

\subsection{Spatial Characteristics of Tweet Sentiment}

The spatial perspective based on the location attributes contained in each tweet showed that as many as 143 out of 363 tweets were uploaded from areas directly affected, covering 13 sub-districts from 2 regencies, namely Pandeglang and Serang (Figure 3 ). The postdisaster conditions were not yet conducive to sufficiently grab the attention of people in the affected areas to be more focused on efforts to evacuate themselves. The areas with rural characteristics were also known to have lower internet penetration rates [40]. This was due to various factors ranging from the capabilities of human resources to communication technology, capital that supports network involvement such as devices, to the availability of existing communication network infrastructure in general. The communities in the directly affected areas which were assumed to have predominantly rural characteristics were generally characterized by closer ties and social interactions in the real world[41]. Furthermore, the use of social media in their daily lives is not as intensive as people with urban characteristics.

Meanwhile, the areas that were indirectly affected by the tsunami generated more tweets during the emergency response period, namely 220 tweets spread across Tangerang City, South Tangerang City, Cilegon City, Serang City, Lebak Regency, and Tangerang Regency. This spatial pattern generally showed that areas with urban characteristics tend to be more reactive on social media in response to an issue[12]. This is supported by technological literacy capabilities and more adequate communication infrastructure capital. 

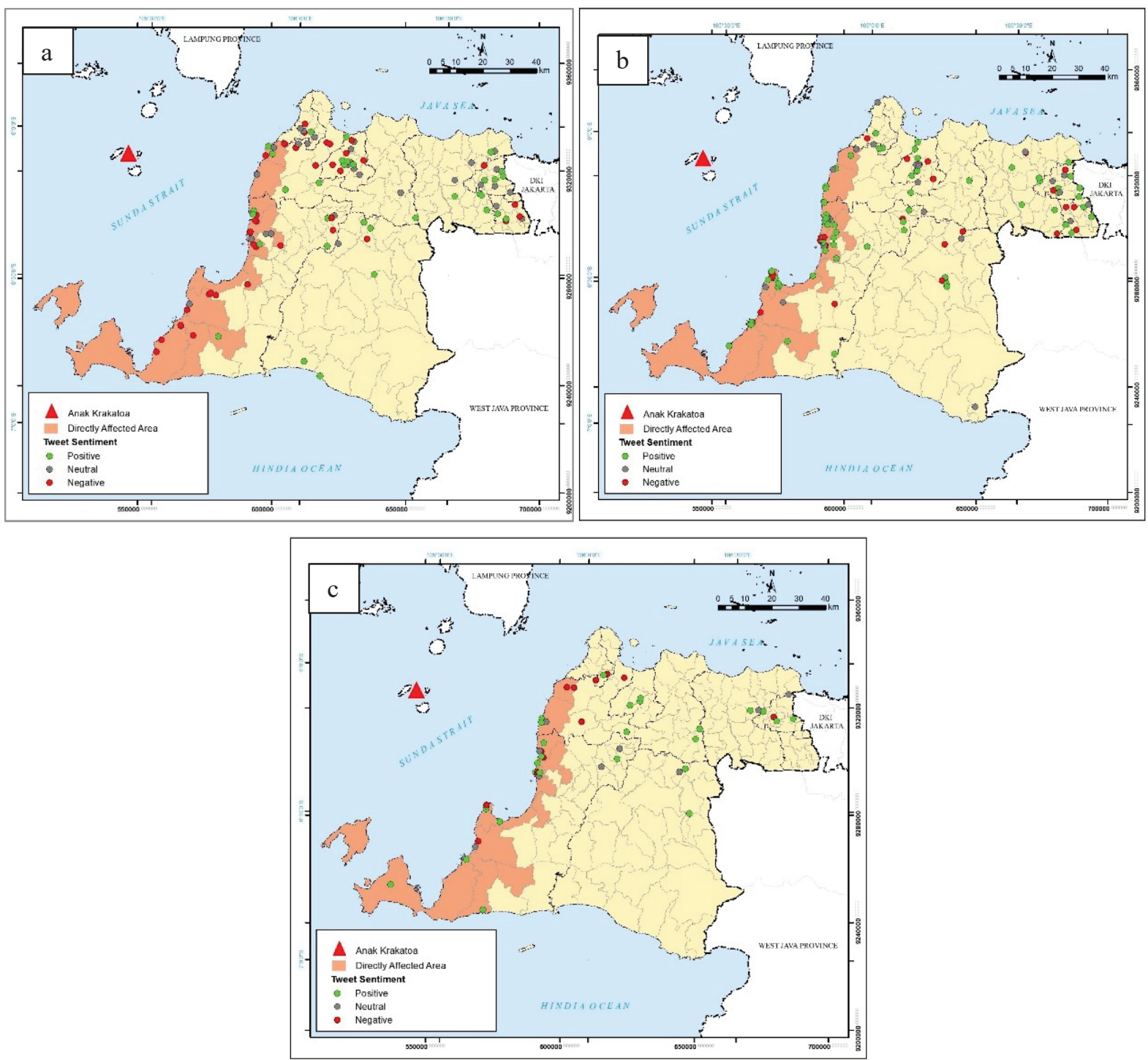

Fig. 3. Spatial distribution of tweet sentiment regarding the Sunda Strait tsunami during Phase 1 (a), Phase 2 (b) and Phase 3 (c)

The tsunami-affected areas showed the dominance of tweets with negative sentiment in Phase 1, namely 22 - 24 December 2018 (Figure 3(a)). This negative sentiment was a manifestation of the response to the tsunami impact. People also tend to be more reactive on social media based on their proximity to the location of the disaster[34]. Tweets with positive sentiment were known to form concentration patterns in urban areas, such as Cilegon City, Serang City, Tangerang City, and surrounding areas. This positive sentiment was manifested in form of expressions of gratitude for safe conditions, sympathy through condolences, and moral support for communities in disaster-affected areas.

Meanwhile, tweets with neutral sentiment did not show any concentration in certain areas in phases 1,2 , or 3 . In phase 2 there was a shift in the concentration of tweets with positive sentiment dominating in disasteraffected areas (Figure 3(b)). This condition showed a shift in the perception of the community that was beginning to accelerate the recovery from the disaster. At the end of the disaster emergency response period, tweets with positive, neutral, or negative sentiments did not show a tendency to concentrate in a particular area in phase 3 (Figure 3(c)). Tweets with positive sentiment were found scattered both in the affected and nonaffected areas, which signified that support for the recovery of the affected areas was still ongoing. Furthermore, several tweets show a distinct sporadic distribution of trend patterns across different phases. The public sentiment during a disaster period does not always reflect the actual impact of disasters they experience because social media users have their own preferences to respond to a disaster topic in a certain sentiment[42]. 


\subsection{Community Emergency Response Towards Sunda Strait Tsunami on Twitter}

\subsubsection{Community Response in Directly Affected Areas}

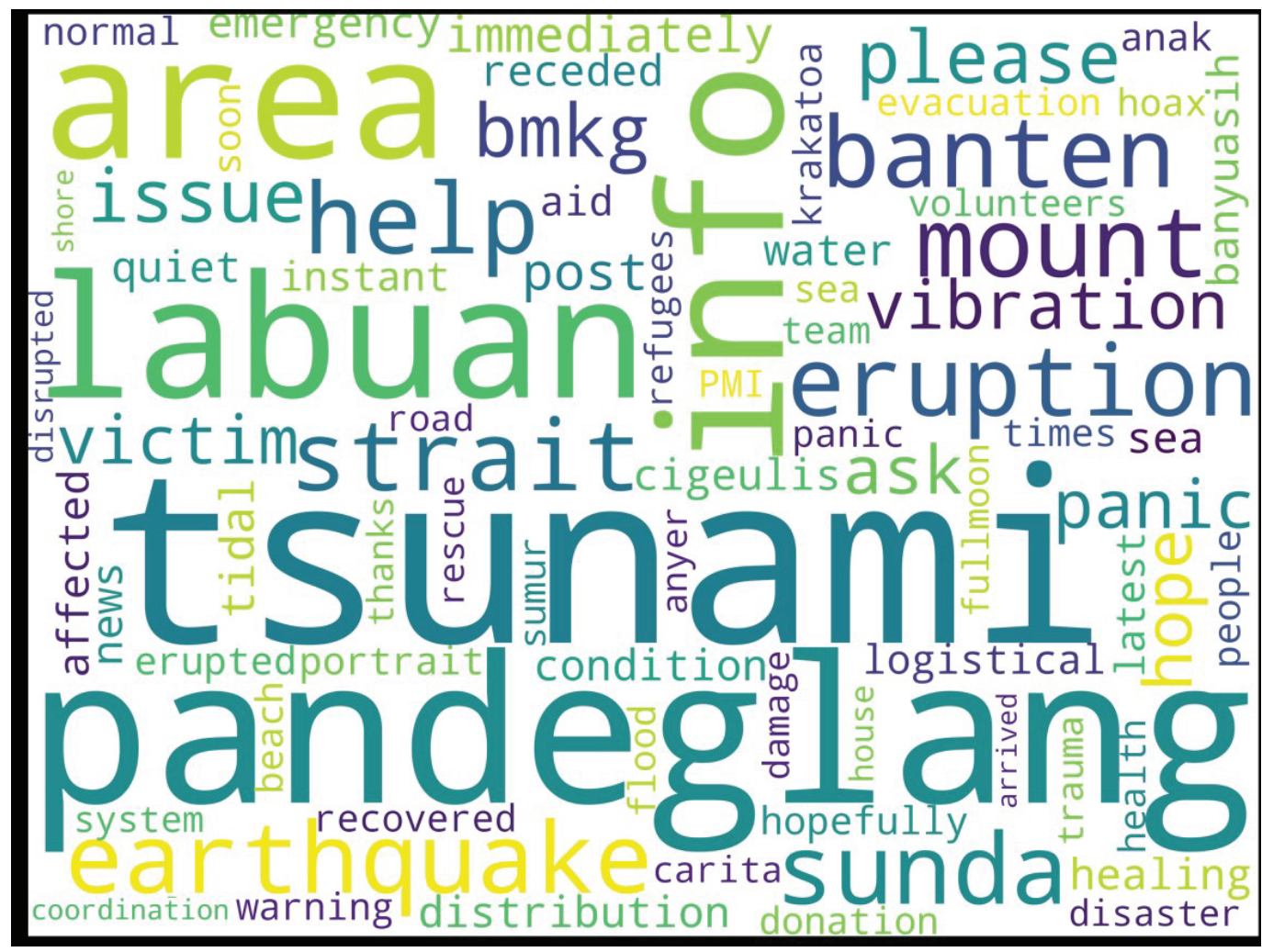

Fig. 4. Wordcloud tweets from people in directly affected by the tsunami areas

Figure 4 shows the wordcloud containing the responses of Twitter users which came from the impact during the Sunda Strait tsunami emergency response period. People living in disaster-affected areas tend to post tweets related to emergencies around them and efforts to save themselves[35]. This sparked public reactions through the words 'ask', 'info', and 'hoax' which represents their confusion and curiosity. This further indicated that people in affected areas were able to use social media to confirm the truth of news from relevant sources. Furthermore, the appearance of the words 'help' and 'please', represented the community's efforts to ask for help. These words also involved reports on the current condition of their surroundings with attached photos or videos and embedding the words 'condition' and 'portrait' alongside the names of the areas being referred to such as 'banyuasih', 'sumur', 'cigeulis' and 'carita'. Several words containing sentimental expressions such as 'panic' and 'hope' represented an anxiety reaction as well as asking for prayer and support when faced with the tsunami disaster.

\section{a. Community Activities and Roles in Directly Affected Areas}

The role-sharing agreement process was not explicitly implied via community tweets. However, based on the actual reportage uploaded by the public shortly after the news of the tsunami disaster, it was observed that there was independent mobility of residents to places that were considered safer. This selfhelp evacuation by the community was carried out in response to avoiding the danger of a tsunami. Hills, fields to places of worship were some of the locations chosen by the community to save themselves based on experiences taught between generations when faced with the tsunami disaster. This collective mobility process was generally coordinated and carried out independently of a person appointed and trusted by the local community. The existence of independent evacuation efforts until the formation of evacuation point clusters signified the collective response of the community which was influenced by the urge to save themselves from the danger of a tsunami. No further information was obtained regarding the process of determining the gathering point for independent evacuation initiated by the community, whether it was a 
collective agreement or an official gathering point directed by the government. However, the community demonstrated the ability and role of local wisdom in identifying the environment and dangers around them. The concentration of the community at easily identifiable points facilitated the process of handling the impact of further disasters by the authorities such as distribution of aid, and further evacuation.

\section{b. Resources Management in Directly Affected Areas}

News of the tsunami disaster in the Sunda Strait attracted a lot of attention from people in various regions. Various forms of assistance and support came from individuals and groups/organizations both in form of volunteers, provision of basic living needs, and donations. The existence of social media was also enabled people in affected areas to report the latest needs required by victims in evacuation. Regarding the fulfillment of basic living needs, the community generally relied on assistance from the government or the results of donations channeled from the nearest post. The post was known to have been established by both government and non-government organizations. Therefore, the role of aid collection and distribution in the affected areas was mostly carried out by volunteers and representatives of government and non-government organizations. Through social media, conversations and tweets (posts on Twitter) reported the most recent conditions and emergency needs at evacuation points. Much of this information was conveyed by official accounts of non-governmental organizations to personal accounts in areas directly affected by the tsunami. The information exchange related to logistical needs at certain points quickly spread through social media and helped the effectiveness of aid distribution, thereby making it more targeted. Sumur Subdistrict in Pandeglang Regency is an example of an isolated area that quickly received assistance after many reports from Twitter users became a trending topic. Assistance received from various sources was managed jointly at government posts and by non-government volunteers, as well as public kitchens scattered in the areas directly affected by the tsunami to meet the needs of refugees.

\section{c. Authoritative Government Role in Directly Affected Areas}

The government through its various functional agencies and institutions carried out a synergistic multi- sectoral disaster management function. Social media accounts belonging to government agencies are one of the sources of information that were relevant and actual in understanding more deeply the emergency response of communities in affected areas. Through these accounts, active emergency response management was carried out by various multi-sectoral lines of government agencies. The national forces collaborating with the rescue team contributed to the evacuation and recovery of vital objects. Furthermore, the Red Cross Association of Cilegon City through@PMI_Cilegon showed their contribution in providing health facilities and basic living needs for refugees. The process of restoration and disaster recovery was mostly informed by the Regional Disaster Management Agency in Serang Regency through @BPBD_Kab_Serang account. This agency showed the process of coordination through meetings to evaluate the acceleration of recovery from the impact of the Sunda Strait tsunami disaster. It was observed that on several occasions the local community participated and worked together in clearing roads from the debris of the tsunami. However, it did not describe in detail the influence of the government in shaping the community's collective behavior significantly.

\subsubsection{Community Response in Indirectly Affected Areas}

Based on Figure 5 below, the responses from unaffected areas were more homogeneous, generally manifested by expressions of gratitude for their safe and secure conditions[35]. These responses showed moral support and invitations to participate in social solidarity actions, as denoted by 'safe', ' condolence ',' hope ', and' prayer. Communities in areas not directly affected by the tsunami were observed to be predominantly urban in nature. Among the tweets posted from areas not affected by the tsunami, some were discovered to originate from the accounts of experts. The head of BMKG, Dwikorita Karnawati, through her account@dwiko_rita, often posted tweets related to developments on the role of BMKG in handling the impact of the Sunda Strait tsunami. Meanwhile, the involvement of experts in providing information through social media also influenced the community's perspective of the disaster. Credible sources of information from experts suppressed the development of fake news which may trigger public panic, thereby ensuring the smoothness of the disaster impact management process. 


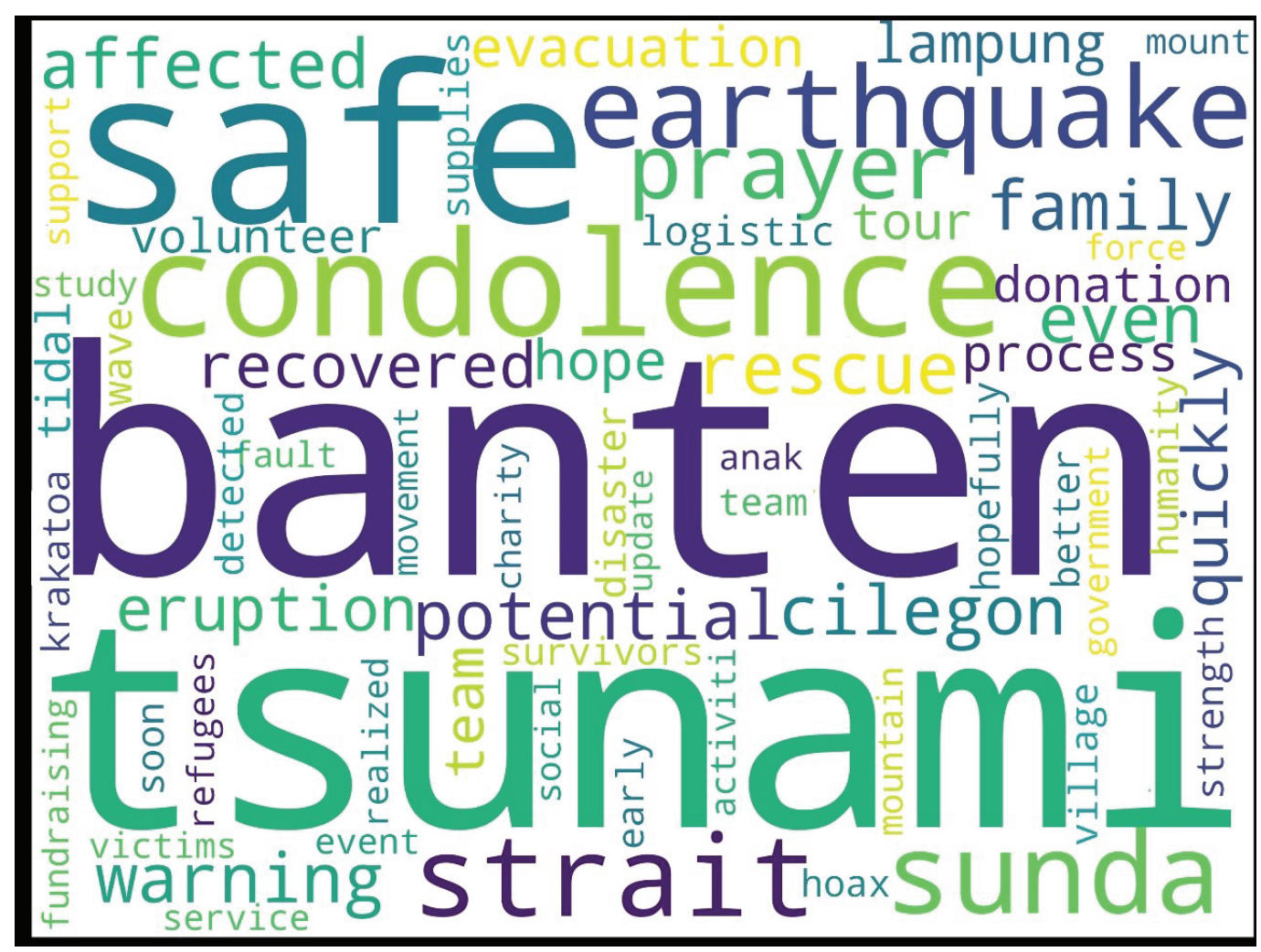

Fig. 5. Wordcloud tweets from people in indirectly affected by the tsunami areas

\section{a. Community Activities and Roles in Directly Affected Areas}

The community activities performed in areas not directly affected were dominated by social actions such as fundraising to charity events, both initiated by individuals and representatives of certain organizations. This showed a mutual response to requests for assistance from people in affected areas which were connected via Twitter. The outpouring of support and prayers conveyed through social media at the same time expanded the dissemination of information on the Sunda Strait tsunami disaster, which helped to increase awareness and generated other similar collective responses. Various fundraising actions to charity events sprung up in various regions which emphasized the growing sense of sympathy for helping victims of the tsunami disaster. Furthermore, support and assistance from communities in areas not directly affected were realized through the donation of resources, both in form of logistics and personal staff as volunteers. This signified the role of social media in gathering and expanding support from various regions for tsunami victims and helping to accelerate the handling of the tsunami impact in the directly affected areas.

\section{b. Resources Management in Indirectly Affected Areas}

The communities in areas not directly affected by the Sunda Strait tsunami distributed aid through collection points initiated by various government and non-government organizations. The collected aid was distributed and delivered by group representatives directly to the affected areas and channeled through the local official posts. Communities from affected areas that contributed to aid distribution generally uploaded some pictures of the aid delivery as a symbol of the task completion report and persuaded the community to also donate to help victims of the disaster on their Twitter accounts. The community also used social media to monitor the conditions and needs of victims in the affected areas to enable efficient, equitable and targeted aid distribution. This signified the existence of mutual interactions carried out by the community in the context of disaster management involving the use of Twitter.

\section{c. Authoritative Government Role in Indirectly Affected Areas}

Involvement of the authorities did not appear to be significant in areas not directly affected by the disaster. The government did not play an intense role in influencing the pattern of community responses in unaffected areas. The role played by the government in areas that were not directly affected generally led to 
efforts to increase awareness by disseminating chronological information. This enhanced the evacuation process by informing on the actual situation of the affected areas through their representatives in the field. Several agencies, for example, the Red Cross Association of Serang City, were also known to receive and manage donations deposited by the community to be distributed to affected areas. Furthermore, through their social media accounts, government agencies supported social movements initiated by the community, including by opening and spreading charity information to help people in affected areas.

Social media connects each user without being limited by space and time. Through it, interactions were formed between people in affected and unaffected areas. The public was also able to easily convey and receive information, which significantly influenced communication efficiency during the disaster. The large exchange of information flows during a disaster period has both advantages and the need for vigilance. Furthermore, information shared by the community in affected areas is important to consider in the formulation of a more effective emergency response strategy. Social media through this phenomenon also shows its role in accommodating social integration and solidarity among people which are physically disconnected in the real world. On the other hand, the government authorities are required to take part in preventing the development of fake news (hoax) which may harm the emergency response process. The existence of official accounts owned by the government as well as contributive experts that conveyed valid and relevant information can help the community in increasing disaster literacy as well as sorting information wisely.

\section{Conclusion}

The Sunda Strait Tsunami was a disaster that massively destructive and suddenly encouraged the formation of collective response in society. The communities in the directly and indirectly affected areas gave different responses. Mutual interaction was formed through social media which connected individuals and groups in the areas directly and indirectly affected. The communities outside the affected area utilized social media for monitoring the current situation and determining locations that still needed assistance from the actual uploads shared by the community in the affected area. The collective community response was manifested in form of social integration and solidarity, which was facilitated by social media. Massive responses and exchange of information on social media during disasters may influence real-world action. However, the limited number of tweets with the geo-tag attribute limited the information that can be explored to further understand the collective response of people on social media, and how it affects their actions.

The author expresses their gratitude to Universitas Gadjah Mada for facilitating the compilation, as well as to D.R. Hizbaron as the supervisor for supporting this research. The topic raised is part of the undergraduate thesis compiled by the author by discussing similar topics in more detail. The author is also grateful to readers for the feedback and constructive suggestions given on this article.

\section{References}

1. A. Muhari, M. Heidarzadeh, H. Susmoro, H. D. Nugroho, E. Kriswati, Supartoyo, T. Arikawa, Pure Appl. Geophys. 176, 5219-5233 (2019) https://doi.org/10.1007/s00024-019-02358-2

2. Syamsidik, Benazir, M. Luthfi, A. Suppasri, L.K. Comfort, Nat. Hazards Earth Syst. Sci., 20, 549-565 (2020) https://doi.org/10.5194/nhess-20-549-2020

3. P.S. Putra, Aswan, K.A. Maryunani, E. Yulianto, S.H. Nugroho, V. Setiawan, Pure Appl. Geophys. (2020) https://doi.org/10.1007/s00024-020-024468

4. M. Heidarzadeh, T. Ishibe, O. Sandanbata, A. Muhari, A.B. Wijanarto, Ocean Eng., 195 (2020) https://doi.org/10.1016/j.oceaneng.2019.106733

5. National Disaster Management Agency (BNPB), Sunda Srait Tsunami. Retrived 25 May 2020, from https://bnpb.go.id/publikasi/infografis/tsunamiselat-sunda.html

6. Humanity Road, Tsunami in Banten Province, Retrived May $29 \quad 2020$, from https://www.humanityroad.org/situationreports/indonesia/indonesia-sunda-strait-tsunami

7. W.L. Farahdita, S.R. Siagian, IOP Conf. Ser: Earth $\begin{array}{lllll}\text { Environ. } & \text { Sci. } & 429 & 012052 & \text { (2020) }\end{array}$ https://doi.org/10.1088/1755-1315/429/1/012052

8. J. Fang, J. Hu, X. Shi, L. Zhao, Int. J. Disaster Risk Reduct. 34, 275-282 (2018) https://doi.org/10.1016/j.ijdrr.2018.11.027

9. M. Jamali, A. Nejat, S. Ghosh, F. Jin, G. Cao, Int. J. Inf. Manage. 44, 25-37 (2019)

10. Muzani, C. Setiawan, M. Zid, F.M. Akmal, IOP Conf. Ser: Earth and Environ. Sci., 412(1) (2020) https://doi.org/10.1088/1755-1315/412/1/012014

11. K. Pongponrat, K. Ishii, Int. J. Disaster Risk Reduct., 27, 133-141 (2018) https://doi.org/10.1016/j.ijdrr.2017.09.047

12. U. Widyanarko, D.R. Hizbaron, IOP Conf. Ser: Earth and Environ. Sci., 451 (2020) https://doi.org/10.1088/1755-1315/451/1/012098

13. S. Coetzee, S. Steiniger, B. Köbben, A. Iwaniak, I. Kaczmarek, P. Rapant, H. Moellering, H., Advances in Cartography and GIS Science. (M. P. Peterson, Ed.), Lecture Notes in Geoinformation and Cartography. Cham: Springer International Publishing (2017)

14. Y.A. Ahmed, M.N. Ahmad, N. Ahmad, N.H. Zakaria, Telemat. Inform., 37, 72-112 (2019)

15. W. Shiau, Y.K. Dwivedi, H. Lai, Int. J. Inf. Manage., 43, 52-63 (2018) 
16. S. Krishna, T. Bhavaraju, C. Beyney, C. Nicholson, Int. J. Disaster Risk Reduct., 39, 101251. (2019) https://doi.org/10.1016/j.ijdrr.2019.101251

17. C. Reuter, G. Backfried, M. Kaufhold, F. Spahr, ISCRAM turns 15: a trend analysis of social media papers 2004-2017, Proceedings of the 15th ISCRAM Conference (2018)

18. Q. Deng, Y. Liu, H. Zhang, H., X. Deng, Y. Ma, Nat. Hazards, 84(2), 1241-1256 (2016) https://doi.org/10.1007/s11069-016-2484-9

19. T.B. Quillinan, F. Brazier, H. Aldewereld, F. Dignum, V. Dignum, L. Pen serini, N. Wijngaards, Developing Agent-based Organizational Models for Crisis Management, Int. Conf. AAMAS, Budapest, Hungary, 45-52 (2009)

20. E. Benjamin, A.M. Bassily-Marcus, E. Babu, L. Silver, M.L. Martin, Mt Sinai J. Med., 78, 306-318 (2011)

21. K. Liao, (2012). Ecol. Soc., 17(4), 48 (2012) http://dx.doi.org/10.5751/ES-05231-170448

22. National Research Council, Facing hazard and disasters: understanding human dimensions, Washington D.C., The National Academies Press (2006)

23. W.N. Carter, Disaster management: a disaster manager's handbook, Manila, Philipines, Asian Development Bank (2008)

24. J. Ingleton, Natural disaster management: a presentation to commemorate the international decade for natural disaster reduction (IDNDR) 1990-2000. Leicester, England: Tudor Rose Insight (1999)

25. B. Wisner, P. Blaikie, T. Cannon, Davis, At risk: natural hazards, people's vulnerability and disasters (sec. edi), Routledge, London (2003)

26. D.R. Hizbaron, N. Ismayani, F.N. Ernawan, N.N.A. Puspitasari, Y. Yulianda, R. Jati, Environ. Dev. Sustain. (2021) https://doi.org/10.1007/s10668021-01249-8

27. G.A. Kreps, Ann. Rev. Sociol., 10, 309-330 (1984)

28. R.A. Stallings, E.L. Quarantelli, Public Adm., 45 (1985)

29. C. Chen, L. Xu, D. Zhao, T. Xu, P. Lei, Saf. Sci, 128 (2020)

30. J. Drury, D. Novelli, C. Stott, Resilience, 1(1), 1837 (2013)

31. C.K. May, Ocean Coast Manage., 169, 86-95 (2019)

32. S.L. Cutter, L. Barnes, M. Berry, C. Burton, E. Evans, E. Tate, J. Webb, Glob. Environ. Change, 18, 598-606 (2008)

33. R.V. Shari, T. Buehner, M.J. Palenchar, J. Contingencies Crisis Manage., 19(2) 110-122 (2011)

34. S. Krishna, T. Bhavaraju, C. Beyney, C. Nicholson, Int. J. Disaster Risk Reduct., 39, 101251 (2019) https://doi.org/10.1016/j.ijdrr.2019.101251
35. J.P. De Albuquerque, B. Herfort, A. Brenning, Int. J. Geogr. Inf. Sci., (April) (2019) https://doi.org/10.1080/13658816.2014.996567

36. A. Acar, Y. Muraki, Y. Int. J. Web Based Communities, 7(3), 392-402 (2011)

37. M. Latonero, I. Shklovski, I., Int. J. Inf. Syst. Crisis Response Manage., 3(4), 67-86 (2011)

38. L. Li, Q. Zhang, J. Tian, H. Wang, Int. J. Inf. Manage., 38, 34-41, (2018)

39. Y. Hu, Geogr. Compass, 12(11) (2018)

40. S. Kemp, Digital 2019: Indonesia DATAREPORTAL - global Digital insights. Retrieved April 06, 2021, from https:/datareportal.com/reports/digital-2019indonesia?rq=digital+2019+indonesia (2019)

41. T. Rockenbauch, P. Sakdapolrak, Ecol. Soc., 22(1) (2017)

42. F. Yuan, M. Li, R. Liu, Int. J. Disaster Risk Reduct., 51(July), $\quad 101798$ https://doi.org/10.1016/j.ijdrr.2020.101798 